\title{
AL CALOR DE UN DISENSO
}

IN THE HEAT OF A DISSENT

\section{Fernando Berckemeyer Olaechea* \\ Exeditor general de THĒMIS-Revista de Derecho \\ Universidad del Pacífico \\ Árbitro independiente}

Dissent in arbitration is often not well-regarded. It is argued that dissenting votes debilitate the authority of the awards and thus that of arbitration since they only promote the career, or vent the ego, of the arbitrator who did not convince the majority. In this paper, the author, contrary to the prevailing opinion, defends the convenience of the dissenting vote as an element which-even when it remains as a slight possibility-serves to the proper functioning of the tribunal as a "mind-of-three".

Consequently, the paper relativizes the data generally used to argue against dissent in arbitration, assesses the different types of dissenting votes and challenges the standards by which the current state of thinking holds this mechanism should be limited and monitored. Instead, the author proposes a system in which "each dissenting vote is the best judge of itself" and where there are only ex post and market dissent controls.

KEYWORDS: Dissent; arbitral award; majority vote; "mind-of-three"; appointment.
En el arbitraje los disensos no suelen ser bien vistos. Se sostiene que debilitan la autoridad de los laudos y, con ella la del arbitraje, sirviendo en los hechos solo para la promoción de la carrera, o el desfogue del ego, del árbitro que no logró convencer a la mayoría. En este artículo, el autor va contra la opinión preponderante y hace una defensa de la utilidad del voto disidente como un elemento que -incluso cuando permanece solo como pura posibilidad-sirve al buen funcionamiento del tribunal como "una mente de a tres".

En ese sentido, el artículo relativiza la estadística que suele usarse para argumentar contra el disenso arbitral, analiza los diferentes tipos de votos disidentes y cuestiona los estándares con los que una importante corriente doctrinaria sostiene se debería limitar y medir a la institución. En su lugar, propone un sistema en el que "cada voto disidente es el mejor juez de sí mismo" y donde los controles de los disensos sean solo ex post y de mercado.

PALABRAS CLAVES: Disenso; laudo arbitral; voto en mayoría; "mente-de-a-tres"; designación.

* Abogado. Master of Laws (LL.M.) por la Universidad de Harvard y Diplomado en Filosofía por la Pontificia Universidad Católica del Perú. Ex director del Diario El Comercio. Ex asociado sénior del Estudio Olaechea y ex asociado internacional de Shearman \& Sterling, LLP. Profesor de la Facultad de Derecho de la Universidad del Pacífico (Lima, Perú). Árbitro independiente. Contacto: fernando@arb-berckemeyer.com.

Nota de Editor: El presente artículo fue recibido por el Consejo Ejecutivo de THËMIS-Revista de Derecho el 11 de abril de 2020, y aceptado por el mismo el 15 de junio de 2020. 


\section{INTRODUCCIÓN}

Las minorías opinadas a menudo no caen bien. Pero en el mundo del arbitraje les va peor que de costumbre. A diferencia de tantos otros espacios de la vida, después de todo, en el arbitraje existen buenos y específicos motivos para justificar que las minorías guarden silencio. No es por gusto que dos de los más respetados autores del campo, Redfern y Van den Berg, hayan escrito sendos y muy citados artículos exponiéndolas (Redfern, 2004, pp. 223-242; Van den Berg, 2010, pp. 821-828), siendo las opiniones del primer autor seminales en el tema, e incluso no ha faltado quien recientemente haya hablado de una "cruzada" contra las opiniones disidentes en el ámbito arbitral (Uluc \& Sutton, 2018, pp. 219-274). Por así decirlo, en el arbitraje no solo es habitual mirar mal a las opiniones disidentes $^{1}$, sino que además se les puede mirar mal con el mejor respaldo doctrinario.

Naturalmente, tampoco deja de haber defensas de las opiniones disidentes. Aunque muchas de ellas las defienden solo parcialmente, es decir, como algo que debería evitarse siempre que se pueda y, en caso no pueda evitarse, limitarse a ser lo que los angloparlantes llaman short and sweet ${ }^{2}$.

En ese sentido, la intención de este artículo es defender la figura de la opinión disidente libre. Cuando hablamos de una opinión disidente libre nos referimos a una que no tenga más límites que los que tiene la mayoría para expresarse en su laudo: la buena fe en base a una diligente comprensión de la ley y los hechos. Además, claro, del límite supuesto por una importante aunque poco practicada regla que -como alguna vez leí en algún lugar injustamente olvidado-debería seguir todo el que escribe: "di lo que tengas que decir y cuando hayas llegado a una oración que tenga punto final, ponlo"3.

Más específicamente, buscamos hacer esta defensa sobre la base de considerar a la institución como útil para garantizar y/o refinar, según sea el caso, el funcionamiento de un tribunal de acuerdo con la que creemos debe ser su esencia: el ser una "mente de a tres".
Antes de desarrollar el punto, sin embargo, es necesario explicar cuál es el fundamento de los argumentos de quienes se oponen al uso -o a todo uso distinto al restringido- de esta figura. Para este objetivo nos centraremos en los antes referidos artículos de Redfern y Van den Berg, en atención a la potencia con la que expresan las ideas centrales de esta corriente de opinión (en adelante, la Corriente) y a los citados que son por ella ${ }^{4}$.

Vayamos a ello.

\section{LAS CRÍTICAS}

Las críticas a la institución del disenso en el campo arbitral pueden resumirse como sigue. Debido a las particularidades propias del arbitraje, en él -a diferencia de lo que sucede en la sede judicialocurre que (i) no hay nada que ganar con el voto disidente; (ii) sí, hay mucho que perder; y, peor aún, (iii) hay actores con incentivos potentes para estar dispuestos a que lo mucho que se pueda perder, efectivamente se pierda.

Como consecuencia de esto, quienes sostienen estos argumentos afirman que el voto de disenso debe ser desincentivado en el arbitraje -"no hay futuro para el disenso en el arbitraje de inversión" llega a escribir Van den Berg (2010, p. 831)- permitiéndose exclusivamente en formatos o en ocasiones sumamente restringidos.

Veámoslo con más detalle.

\section{A. Nada que ganar}

Se sostiene que no hay nada que ganar ni para el proceso ni para las partes que lo contratan, que son lo importante. Como bien lo resume el siempre elocuente Redfern,

el propósito del arbitraje es llegar a la decisión. Es la decisión la que importa [...] cuando un laudo es emitido, la primera acción que las partes y sus abogados normalmente toman es ir al final del documento para ver si ganaron o no (2004, p. 236)

1 Para fines de este artículo utilizaremos indistintamente "disenso", "voto disidente" y "opinión disidente". En todos los casos nos estaremos refiriendo a esta última, es decir, al voto disidente que es expresado por escrito en una opinión.

2 La traducción de esta expresión vendría a ser "corto y dulce", pero no la consignamos en español en el texto porque es una frase que pierde su gracia al traducirse.

3 En criollo: "no palabrees".

4 Creo no equivocarme si digo que no me he encontrado con un solo texto académico sobre el disenso que tenga algún buen nivel de difusión y que no cite ambos artículos o, en su defecto, a alguno de los otros lugares donde Redfern o Van den Berg han expresado las ideas de estos dos textos (incluyendo, en las partes en que abordan el disenso arbitral, a los manuales canónicos del arbitraje, como los de Born, Lew o González de Cossío).

5 La traducción es nuestra, como todas las demás traducciones del artículo que no sean citas sacadas de fuentes secundarias que escriben en español y que han traducido los textos que citan. 
Dicho de otra forma, habida cuenta de que con los votos de la mayoría -o, cuando corresponde, del presidente- ya hay decisión en el caso, una vez producida esta, lo demás sobra. Está fuera del contrato entre las partes que dio origen y justifica al arbitraje.

Ciertamente, no se dan en el campo del arbitraje las mismas ganancias que sí produce un disenso en un proceso judicial. Ahí, cuando el voto disidente se genera en una instancia apelable, este puede servir a una garantía que es propia del proceso: la revisión por una instancia superior. Y cuando se da en última instancia, tiene también el potencial de servir a una función propia de la judicatura: ayudar a cambiar la ley. Esto, porque un disenso puede ser tomado en cuenta por otros tribunales para cambiar el precedente en el caso del common law, o por el legislador, tanto en el common como en el civil law.

Ninguna de estas cosas se da en un proceso arbitral, en el que lo que las partes buscan es la velocidad de la única instancia y la función del tribunal es estrictamente privada. El tribunal arbitral, a diferencia del judicial, no trabaja para la sociedad en su conjunto.

Por si esto fuera poco, en el tema específico de los arbitrajes comerciales tenemos que la gran mayoría de casos tiene como objeto principal la interpretación disímil de hechos, y sobre hechos no hay precedentes que establecer (a diferencia de cuando hablamos de interpretación del derecho). Además, en ellos prima la confidencialidad ${ }^{6}$.

Desde luego, que el arbitraje en sí no gane nada con el voto disidente no quiere decir que el árbitro en minoría no tenga algo que ganar de este. Pero eso ya no trata del arbitraje, sino de la carrera del árbitro en cuestión. Para cumplir con aquellos móviles de este árbitro que puedan ser considerados legítimos y salvaguardar, por ejemplo, su conciencia o su coherencia intelectual frente a las partes, basta lo que Redfern propone como el único disenso bueno: uno "corto, amable y controlado" (2004, p. 239) 8 .

\section{B. Mucho que perder}

Ahora bien -continúa la Corriente- si no hay nada que ganar con el voto disidente en un arbitraje, sí hay mucho que perder. Se entiende, en efecto, que en el arbitraje la opinión disidente no solo sobra, sino que inclusive estorba. Al fin y al cabo, ese extra a lo que las partes contrataron que uno entrega con un voto disidente constituye una muestra de división en el tribunal. Y esa división golpea más a un laudo de lo que podría golpear a una sentencia judicial porque, como apunta Redfern, a diferencia de la sentencia de un juez que tiene detrás de sí la reputación de todo el sistema judicial -con su carrera profesional y sus sistemas de nombramiento, apelaciones y control- "la autoridad de un tribunal arbitral depende exclusivamente del propio tribunal" (2004, p. 233).

Peor aún, el voto disidente no solo resta peso al laudo, sino que en los casos en que cuestiona que el debido proceso haya sido respetado en el arbitraje, puede servir para anularlo ${ }^{9}$. Es decir, pueden llegar a suceder precisamente dos de las cosas que se buscan evitar cuando se opta por un arbitraje: que se introduzca a los jueces en el tema y que haya más que una instancia. Un peligro, vale la pena precisarlo, que solo crece cuando existen cortes que aceptan que se empuje por la puerta del debido proceso argumentos que versan sobre el fondo del asunto, como ocurre habitualmente con las anulaciones por "defecto de motivación".

Este último problema -esto es, el voto disidente como una brecha abierta al interior de la muralla del laudo para que los enemigos de este puedan penetrarlo y destruirlo- es la preocupación principal de los críticos de la figura. La otra preocupación que tampoco debe perderse de vista es la confidencialidad de las deliberaciones.

Ninguna de ellas es teórica: los dos peligros de la opinión disidente frecuentemente se concretan en la realidad y, a menudo, al mismo tiempo.

Un ejemplo muy citado es el del voto disidente de CME Czech Republic c. República Checa (2001),

$6 \quad$ Esta última característica tiende a relativizarse: el arbitraje comercial cede cada vez más a las exigencias de la publicidad. Un magnífico ejemplo es el Faro de Transparencia que, siempre preservando los nombres de las partes, inauguró en el año 2019 la Cámara de Comercio de Lima.

7 Los arbitrajes de inversión, donde los laudos son públicos, no están sujetos a la misma confidencialidad que los arbitrajes comerciales. Además, parece haber en ellos mayor espacio para el precedente pues, al estar basado el sistema internacional de protección de inversiones en tratados con contenidos a menudo estandarizados, aparecen constantemente las mismas preguntas jurídicas en los diferentes arbitrajes. Así y todo, Van der Berg anota que, como regla general, "en los arbitrajes de inversión los hechos constituyen el $80 \%$ del caso" (2010, p. 824).

8 Según el autor, este es el único tipo de voto disidente bueno.

9 Como se sabe, solo una afectación al debido proceso (entendido en el sentido arbitral) permite anular un laudo en las legislaciones pro-arbitraje, entre las que se incluye la peruana (Decreto Legislativo 1071, 2008, art. 63). 
en el que el árbitro usó su voto de disenso para sostener que el debido proceso había sido violado en el arbitraje, pues él había sido excluido de las deliberaciones por los otros dos árbitros. La parte perdedora del arbitraje (la misma que había nombrado al árbitro que emitió el disenso) llevó el caso ante una corte de apelaciones sueca y todos los árbitros terminaron desfilando frente a ella para dar su testimonio. Al final la corte mantuvo la validez del laudo porque entendió que más que haber sido excluido de las deliberaciones, el árbitro estaba intentado prolongarlas indefinidamente. Ello, no obstante, en el camino de rechazar el pedido de anulación del laudo, se acabó con la confidencialidad de las deliberaciones del proceso.

Asimismo, otro ejemplo importante y más reciente, es el de Vantage Deepwater c. Petrobras America (2018), en el que James M. Gaitis -un árbitro que también fue nombrado por la parte perdedora- escribió que la forma en la que se habían llevado a cabo las etapas del arbitraje violaba el derecho del demandado al debido proceso. Así, se habría incurrido en una de las cuatro causales de anulación contempladas por la Ley Federal de Arbitraje de los Estados Unidos (Federal Arbitration Act, 1926) incluyendo las referidas a corrupción ${ }^{10}$. En este caso, el juez federal se negó a escuchar el testimonio de Gaitis, expresando que ello lo obligaría a también escuchar a los otros árbitros ("un descubrimiento lleva a más descubrimientos") y que esto perjudicaría la confidencialidad del proceso. El escueto disenso de Gaitis, mencionó el juez, no daba ninguna evidencia para sustentar su acusación y, sin evidencia, el juez no estaba dispuesto a levantar la confidencialidad del proceso y poner en duda el laudo (Cassady, 2018).

En el Perú hubo también un caso similar recientemente: Blue Oil Trading Ltd c. Pure Biofuels del Perú (2014). Este laudo conllevó el voto disidente del árbitro nombrado por la parte perdedora, Hugo Forno, quien sostuvo que se le había negado la posibilidad de participar de las deliberaciones. Aunque Pure Biofuels pidió la anulación del laudo, el Poder Judicial sostuvo que Forno había tenido suficiente oportunidad de expresar sus argumentos al Tribunal (Expediente 0244-2014, 2015) ${ }^{11}$.

\section{Un interesado en echarlo a perder}

Pese a todo lo anterior, lo que causa mayor preocupación no es tanto que un proceso arbitral no tenga nada que ganar de una opinión disidente, ni que pueda ser tan frágil como para no resistirla sin perder peso -o sin seguir vivo en los casos de anulación. No. Lo que vuelve la situación verdaderamente preocupante a ojos de los exponentes de la Corriente es la presencia estructural en el arbitraje de un personaje con algo que ganar para sí de un disenso y una eventual anulación: el árbitro cuya parte perdió. Una persona que debe su nombramiento a esta parte y su empleo en general, como todo prestador de servicios, a la satisfacción de quienes lo contratan (ya sea porque vuelven a contratarlo, o por las referencias que dan de él). Alguien, esto es, con buenas razones para volverse el quintacolumnista del arbitraje y que cuenta, gracias al disenso, con un buen instrumento para serlo.

Esta persona, tal como lo afirma Van der Berg, es la "raíz del problema" del disenso en el arbitraje.

Tenemos, pues, que en el fondo el problema es el que plantea la figura del árbitro de parte en sí: el problema del juez que es nombrado por una de las partes a las que juzgará. Hay ahí una contradicción en los términos porque hay una contradicción en los intereses. De esta forma, a la frase del Talmud que afirma que "un juez que es escogido por una parte buscará argumentos para favorecerla", la Corriente añadiría "y los expresará en una opinión disidente".

Tanto Redfern como Van der Berg muestran la vigencia contemporánea del presagio del Talmud mediante la estadística arbitral de voto disidente.

Sobre la base de una charla dada en 2003, Redfern señala que en el año 2001 hubo 24 opiniones disidentes acompañando los laudos de la Cámara de Comercio Internacional (en adelante, $\mathrm{CCl}$ ) de París. De esas 24 opiniones, 22 fueron emitidas por árbitros elegidos por la parte que perdió y a favor de la posición de esta (2004, p. 234).

Por su parte, Van den Berg, que escribe en el 2010, contempla los 150 laudos de arbitrajes de inversión que en ese momento figuraban en las páginas del Institute for Transnational Arbitration (ITA) y el Centro Internacional de Arreglos de Diferencias Relativas a Inversiones (CIADI). Había 34 votos disidentes. De esos 34, el 100\% habían sido emitidos por el árbitro de la parte que perdió (2010, pp. 824,837 y ss.).

10 Gaitis citó en el disenso los cuatro artículos correspondientes de la ley.

11 Cabe resaltar, que, si bien todos estos ejemplos terminaron sin anulación, otros la han conseguido. El ejemplo típico de esta especie de disensos en el arbitraje de inversión es el caso Klöckner c. Camerún, donde el comité ad hoc del Centro Internacional de Arreglo de Diferencias Relativas a Inversiones anuló el laudo basado en el disenso del árbitro de la parte que perdió. 
Van den Berg también recopiló la estadística de la $\mathrm{CCl}$ posterior a la de Redfern. Descubrió lo mismo: del 2004 al 2008 todos los votos de disenso emitidos, con excepción de dos, fueron dados por el árbitro de la parte que perdió (2010, pp. 832-833, 837).

Las cifras analizadas con posterioridad a las investigaciones de ambos autores solo confirman sus conclusiones. Por ejemplo, en el período comprendido entre el 2009 y el 2011 hubo disensos en el $16 \%$ de los casos de la $\mathrm{CCl}$. De este porcentaje, únicamente el $1 \%$ de ellos no fue producido por el árbitro nombrado por la parte que perdió (Fry et. al. citados por Sönderlung, 12 de marzo de 2019).

Con estas cifras, el argumento de la Corriente puede ser presentado de la siguiente manera. Si bien "el papel aguanta todo", no solo está claro desde el punto de vista teórico que no hay nada que ganar de un voto disidente en un arbitraje, sino que en los hechos se observa que los árbitros de la parte perdedora son casi los únicos que disienten. Dicha coincidencia es demasiado gruesa -o "asombrosa", como la llama Van den Berg (2010, p. 824)como para no pensar que el punto de quiebre que lleva a un árbitro a disentir es el querer quedar bien con la parte que lo nombró (lo que puede incluir, como en los ejemplos citados, darle pie para seguir luchando por el tema en los tribunales). Si fuese cualquiera de las otras posibles causas la que detonase los disensos -el ego del árbitro cuyos argumentos no convencieron a la mayoría, por ejemplo-, tendríamos presidentes y árbitros nombrados por la parte ganadora disintiendo. Ergo, queda claro que en la práctica el disenso funciona casi exclusivamente como un instrumento de promoción en el mercado de los árbitros de parte.

\section{La propuesta de los críticos}

Como consecuencia de la situación así descrita, parecen quedar solo dos tipos de respuestas razonables. $\mathrm{O}$, como propone Redfern, los disensos se limitan a su versión short and sweet; o, como propone Van den Berg, no se les pone límite de contenido, pero sí un límite de ocasiones que limite su uso exclusivamente a los casos más graves.

De hecho, Van den Berg cree que los votos disidentes solo se deberían de dar en dos situaciones específicas: o cuando "algo fue fundamentalmente mal en el proceso arbitral, por ejemplo, hubo una muy seria violación del debido proceso", o cuando "el árbitro ha sido amenazado con que, si no hay disenso, él o ella estará en grave peligro físico" (2010, p. 831) $)^{12}$. No existirían límites para un árbitro que se encuentra en uno de estos dos casos: para esas dos situaciones extremas sí parece creer no solo en el disenso, sino en el disenso libre.

Si bien no existen muchas jurisdicciones que prohíban el disenso ${ }^{13}$, el efecto mayor de los argumentos de la Corriente está en la generación o el sostenimiento de una cierta manera de mirar el voto disidente en el arbitraje: lo que con razón se ha denominado "un estigma" (Uluc \& Sutton, 2018, p. 274) $)^{14}$.

\section{NUESTRO ANÁLISIS}

No es de sorprender que, habiendo encontrado expresión en boca de tan importantes tratadistas, los argumentos contra la opinión disidente arbitral sean potentes y parezcan cerrar de manera contundente su caso con una estadística difícil de rebatir.

Vistos con detenimiento, sin embargo, empiezan a ofrecer algunos agujeros significativos.

Veamos.

\section{A. Los números exhibidos, siendo elocuentes, muestran menos de lo que parece}

Para que las estadísticas sean efectivamente confiables en sus mensajes hay que recopilar todas aquellas que sean relevantes sobre la realidad de la que se quiere hablar. La data de un reciente estudio titulado "You only dissent Once: Reappointment and Legal Practices in Investment Arbitration", que busca sustentar estadísticamente un punto contrario al expuesto por Redfern y Van den Berg, me hizo recordar esto (Strehtnev, 2015).

¿Cuál es la tesis de este artículo? Pues que el mercado castiga a los árbitros que disienten para efectos de sus eventuales nombramientos como presidentes de tribunales arbitrales, lo que ocasiona que comparativamente existan pocos disensos en el arbitraje de inversión en comparación con las sedes judiciales.

La existencia de este castigo se deduce de la estadística que el autor da a conocer sobre disensos y redesignaciones en los tribunales del CIADI: Ios árbitros que disienten tienen, en promedio, tres veces menos posibilidades de ser luego nombrados como presidentes.

\footnotetext{
12 Redfern se refiere a "otros caminos" para este tipo de "insatisfacción”, como renunciar al arbitraje (2004, p. 230).

13 Born alude a algunas jurisdicciones, pero no da los ejemplos (2014, p. 3055).

14 También es elocuente la frase "efecto estético" que usa Arroyo (2008, p. 446).
} 
Es cierto que los números que enseña el autor también muestran que este resultado no se da si se trata de ser luego nuevamente nombrados árbitros de parte, mas no por eso deja ser el suyo un dato nuevo que agrega información a la estadística de la Corriente.

Luego de este dato, ya no tenemos una, sino dos fuerzas simultáneas en un mismo mercado: una que incentiva a los árbitros de parte a disentir a favor de la posición de quien los nombra y otra que desincentiva a disentir a todos los que quieran ser en algún momento presidentes. Es difícil establecer qué tan grande es esta segunda fuerza pues su influencia se traduce en un no-hacer, pero no ha de ser menor si tomamos en cuenta el porcentaje de disensos que se da en los tribunales arbitrales frente a los judiciales ${ }^{15}$.

Tendría sentido que esta fuerza anti-disenso provenga del valor que el mercado del arbitraje asigna a la colegialidad como pilar de la autoridad del laudo por razones como las que expone la Corriente. Sea como fuese, el hecho es que su sola existencia muestra que el sistema tiene más balance de lo que muchas veces se pinta. No es en vano que la mayoría abrumadora de laudos sigue sin tener votos disidentes a pesar de que en todos ellos hay un árbitro nombrado por una parte que perdió. En el procedimiento de nominación de los tribunales arbitrales - por el que cada parte nombra a un árbitro y luego los dos, en conjunto, al presidente- hay más sabiduría -más frenos y contrapesos- que lo que las críticas al mismo, como las de Redfern y Van den Berg, harían pensar.

El sistema, en realidad, hace que el voto partidista solo presente ventajas para quienes apuestan por hacer una carrera exclusivamente como árbitros de parte; a los demás puede complicarles seriamente la parte del mercado que supone el cargo de presidente del tribunal arbitral.

Todo parece apuntar, por otra parte, a que la medida en que un disenso de este tipo puede ayudar a la carrera de un árbitro de parte está condenada a ser cada vez menor. Después de todo, no siempre estuvo igualmente claro para todos hasta qué punto un árbitro nombrado por una parte tenía respecto de ella las mismas obligaciones que respecto de su contraparte.
Pensemos, a modo de ejemplo, cómo hasta el año 2004 el Código de Ética para Árbitros en Disputas Comerciales que promulgan en común la American Arbitration Association y la American Bar Association presumía la no-neutralidad de los árbitros nombrados por las partes ${ }^{16}$. También cómo hasta hoy existe autorizada doctrina que sostiene que los árbitros de parte, aunque sometidos a los deberes generales de imparcialidad e independencia, tienen algunos deberes especiales para con su nominadora; principalmente, el de asegurarse que la posición de esta sea bien entendida por el resto del tribunal. Los comentadores en el arbitraje internacional muchas veces consideran esto una expresión del rol de traductor cultural que tiene el árbitro de una parte, asumiendo que sea de la misma nacionalidad de esta ${ }^{17}$. Una obligación resbalosa, en el mejor de los casos, si vamos a hablar de igual independencia e imparcialidad.

Resulta lógico pensar que conforme se afiance el cada vez mayor consenso sobre la posición respecto a que no deberían existir diferencias de ningún tipo entre los deberes de todos los árbitros del tribunal, tendrá menos que ganar en el mercado quien emita un voto disidente con el ojo puesto en -o más bien guiñado a- futuras posibilidades de nombramientos.

\section{B. Sí hay algo que ganar}

Más allá de todo esto, sin embargo, lo relevante no es la causa que mueve al voto disidente, sino el determinar si este no tiene nada valioso que aportar al proceso arbitral en el que se produce cuando tiene buenos argumentos (más allá de que tenga algo que aportar también al árbitro que lo emite).

Si el voto disidente aporta al proceso arbitral, la preocupación real no debiera ser cómo combatirlo, sino cómo hacer para que no exista un miedo a emitirlo. Esto es, cómo hacer para disolver el estigma.

Pues bien, ¿tiene o no el voto disidente algo que aportar al proceso en el que se emite?

Hay algo que poseen en común todas las utilidades que el voto disidente presenta en un tribunal judicial y que la Corriente señala con razón como aspectos no trasladables al arbitraje (sus usos en la apelación, en la generación de jurisprudencia y

15 Strezhnev cita como un ejemplo el caso de la Corte Suprema de los Estados Unidos, que tiene una tasa de disensos de $62 \%$ (2015, p. 2). Esto, pese a que algunos de sus miembros que más recurrentemente firman disensos reconocen que en su institución sigue siendo verdad que la unanimidad ayuda a la autoridad de las decisiones: "Ciertamente concuerdo con que la unanimidad es importante para lograr cierta legitimidad del público" (Scalia citado por Saldaña Cuba 2012, p. 147).

16 La presunción de neutralidad está en el Canon IXa. Según el Código de 1970 (Canon VII) como el actual (Canon X), los árbitros no neutrales pueden estar "predispuestos" a favor de las partes que los nombraron, aunque están sujetos a los mismos deberes de buena fe, integridad y justifica para llevar el proceso y decidir en él.

17 Ver por ejemplo a Lew, Mistells \& Kröll (2003, pp. 258-259). 
en la inspiración de la ley futura). Todos esos aportes se dan luego de producida la decisión del tribunal. Es decir, los críticos del disenso arbitral no toman en cuenta, o lo hacen solo con ligereza ${ }^{18}$, el rol que voto disidente puede jugar antes del momento en que se da la decisión en el arbitraje, a fin de determinar el contenido y la calidad de la misma. En otras palabras, toman en cuenta el rol del voto al exterior del proceso (o de la etapa judicial) del que se trate, pero no el que puede tener al interior del mismo.

¿Cuál es, entonces, el rol que cumple el voto disidente al interior del proceso?

Son, de hecho, dos. El que cumple cuando es efectivamente emitido y el que cumple por el solo hecho de existir como posibilidad.

El voto disidente, al fin y al cabo, se asimila a un arma y, como se sabe, las armas no necesariamente tienen que ser disparadas para lograr cambios en las conductas de las personas. A menudo basta con que se sepa que están ahí.

Más específicamente, la función del voto disidente como pura posibilidad al interior del proceso es la siguiente: poner presión sobre los árbitros de una eventual mayoría que no quiera prestar la debida atención a los argumentos de la minoría. La existencia del voto disidente dice a esa mayoría "esos argumentos que ustedes no quieren oír ahora sí podrán ser oídos por las partes y sus abogados". Cuanto mejores sean los argumentos del árbitro de la minoría y cuanto menor respuesta tengan en los de la mayoría, más grande es lo que se juega esta última si no quiere escuchar a aquel.

Se puede pensar que a la parte que no nombró al árbitro disidente y a sus abogados no les causará efecto alguno la posibilidad de que lo anterior suceda. Pero eso sería creer que la vida se acaba en el proceso en cuestión. Esos mismos abogados estarán en el futuro volviendo a escoger árbitros y, antes de saber si ganarán o perderán, se hallarán interesados en la pericia técnica e imparcialidad de los candidatos que considerarán.
Por otra parte, cuando hay una exclusión total de las deliberaciones en el proceso, el mensaje que la posibilidad de un voto disidente plantea también puede ser más crudo y corto: "esto se va a saber". Este es el segundo tipo de disenso: el disensoacusación, usado ya no para discrepar de los argumentos sobre el fondo de la mayoría, sino para acusarla de haber violentado el debido proceso, como ocurre cuando se le niega la deliberación a un árbitro. Como hemos visto, fue para concretar esta posibilidad que los árbitros de los casos $C M E$ Czech Republic c. República Checa (2001) y Blue Oil Trading Ltd c. Pure Biofuels del Perú (2014) terminaron utilizando sus votos disidentes (hablaremos más de la pertinencia de este segundo tipo de voto disidente líneas abajo).

Nada de esto, por supuesto, faculta al árbitro a alargar eternamente las deliberaciones ¿En qué momento se considera que un árbitro que no está de acuerdo con la mayoría ha tenido una oportunidad significativa de ser escuchado? ¿cuál es la debida atención ${ }^{19}$ que debe prestar la mayoría? No hay una fórmula exacta para contestar estas interrogantes: la única manera de responderlas es viendo en cada caso concreto si los argumentos del árbitro que afirma no haber sido escuchado están contestados o no -siquiera implícitamente-en la opinión de la mayoría. Es decir, comparando el voto de la mayoría con el voto disidente.

Ciertamente, puede que la posibilidad de un voto disidente no sea suficiente en muchos arbitrajes para lograr el efecto descrito, pero sin este instrumento un árbitro al que no se quiere escuchar "por las buenas" está absolutamente desprovisto de mecanismos para hacer valer su derecho y obligación de aportar a la deliberación ${ }^{20}$. Hay que tomar en cuenta, además, que conocemos los casos de opiniones emitidas por quienes denuncian no haber podido participar de las deliberaciones, o haber podido participar solo formalmente. No conocemos, en cambio, aquellos en los que la opinión disidente no tuvo que ser emitida porque su sola posibilidad alcanzó para que la deliberación se diera. Es decir, por definición, no tenemos manera de saber cuántas veces cumple su función el voto

18 El caso de van den Berg es notable en este sentido (2010, p. 823).

19 Born habla de "una oportunidad significativa de expresar sus objeciones" [el énfasis es nuestro] (2014, pp. 160-161) para decir lo que una mayoría debe al árbitro que discrepa de ella a fin de cumplir con el debido proceso.

20 Ni el árbitro disidente de CME Czech Republic c. República Checa (2001) ni el de Blue Oil Trading Ltd c. Pure Biofuels del Perú (2014) vieron el laudo anularse, pero sí se han anulado laudos por ausencia de una deliberación real (para ejemplos de ello ver Born, 2014, p. 3247, nota 492).

Lógicamente, esto en modo alguno quiere decir que el derecho a participar significativamente de las deliberaciones pueda ser usado por un árbitro de mala fe para demorar injustificadamente el proceso o aún para ponerlo en riesgo. Hay un examen de razonabilidad a hacerse en las circunstancias de cada caso concreto y sobre la base de este, muchas cortes, incluyendo las de los dos casos antes citados, han denegado la anulación pese a la acusación del árbitro que dijo haber sido impedido de deliberar. Sobre este particular ver Born (2014, p. 3248, nota 494). 
disidente entendido como pura posibilidad. Pero sí sabemos que está ahí, en el inconsciente del tribunal: en el del árbitro en minoría que quiere que se le escuche bien y en el de la mayoría que encontraría más práctico proceder sin él.

Es importante precisar aquí que aun cuando el arma del disenso se dirija contra los árbitros de la mayoría, esta actúa en realidad más que a favor del árbitro de la minoría que lo emite, a favor del proceso en sí. Ello, en la medida de que una de las principales razones para elegir a un tribunal en lugar de a un solo árbitro es aquella que está detrás de la sabiduría popular cuando sostiene que "dos mentes piensan mejor que una" (aunque se suela expresar más técnicamente ${ }^{21}$ ).

Para decirlo metafóricamente, cuando las partes constituyen un tribunal construyen un aparatopara-pensar (su caso) que tiene sus propias especificidades ${ }^{22}$. Concretamente, constituyen lo que, según adelantamos, podría denominarse como una "mente de a tres"23 que, igual que cualquier "mente" colectiva, solo puede funcionar contrastando las ideas que cada una de sus partes produce, cambiándolas o dejándolas de lado según cómo unas influencien a otras, y quedándose finalmente con aquellas que sobrevivan a todo el proceso. Si las ideas de una de las tres partes no son tomadas en cuenta para ese contraste y síntesis, hay toda una perspectiva (ya sea jurídica o de índole más personal) que deja de estar presente y la máquina no funciona debidamente. No funciona, esto es, como se acordó que funcionaría al diseñarla.

Pues bien, la existencia del voto disidente como posibilidad aumenta las posibilidades de que los argumentos de todos los árbitros sean tomados en cuenta $y$, por lo tanto, de que la mente-de-a-tres funcione.

Ahora bien, si esta es la función del voto disidente como posibilidad, ¿cuál es su función una vez ya concretado? Pues subir la presión para que tenga lugar al aquilatamiento en serio de las opiniones de la minoría. No solo porque una vez que el disenso ya se escribió se incrementa la posibilidad de que partes y abogados conozcan los argumentos no tomados en cuenta por la mayoría; sino, más importante aún, porque el blanco y negro supone en sí un test más ácido a la hora de intentar responder estos argumentos. Con lo que, una vez escrito, el voto disidente no funciona únicamente contra la mayoría que se niega a tomar en cuenta seriamente a la minoría, sino también contra aquella mayoría que de buena fe deliberó con el árbitro en minoría sin llegar a calar bien sus argumentos. Como acertadamente ha dicho Gary Born:

One of the reasons for requiring a written, reasoned award is precisely to force the tribunal to articulate its conclusions and reasoning in black-and-white.

In a surprising number of cases, views that were expressed confidently in oral discussions "just won't write": equally views that are expressed in a draft award will, in some instances, not withstand the force of a careful dissenting opinion (2014, p. 3059).

Por así decirlo, si la posibilidad del voto disidente sirve para hacer más difícil que se obstaculice el funcionamiento de la mente-de-a-tres, volviéndola una de a dos; el voto disidente, una vez expresado en blanco y negro, tiene la utilidad añadida de servir para "sacar punta" al funcionamiento de esa mente-de-a-tres. Una sacada de punta que no necesita para ser valiosa de cambiar el sentido de la decisión final que esta mente tome (aunque pueda hacerlo).

Hay muchos testimonios de cómo funciona este último efecto al interior de los tribunales, incluyendo testimonios de su valor aun en los casos en los que el voto disidente no llegó a convencer a la mayoría de cambiar el sentido de su decisión. Entre ellos podemos encontrar los de esos dos grandes rivales ideológicos al interior de la Corte Suprema estadounidense (y grandes amigos en lo personal) que fueron Ruth Ginsburg y Antonin Scalia.

\section{Dice Ginsburg}

Mi experiencia me ha enseñado que no hay nada mejor que un buen disenso para guiar al autor de la opinión mayoritaria a refinar y clarificar su dirección inicial. [En una ocasión] fui designada para redactar la opinión de la Corte. El resultado final, presentado públicamente, fue mucho mejor que mi primer, segundo, y al menos, una docena de proyectos, gracias al persuasivo disenso del juez Scalia (Grinsburg citada por Saldaña Cuba 2012, p. 151).

\section{Scalia escribe:}

El disenso pone a prueba mi opinión, permitiendo una confrontación directa entre los mejores argumentos de ambas partes sobre los

21 Ver por ejemplo a Lew, Mistells \& Kröll (2003, pp. 227-228).

22 Estas, desde luego, incluyen las reglas procesales que ellas pongas y que estipulan, por ejemplo, las etapas y los tiempos en que deberá pensar esa mente.

${ }_{23}$ Tres, en la enorme mayoría de los casos: existen los tribunales con más árbitros, aunque no parecen muy prácticos en circunstancias normales. 
puntos controvertidos. Por irónico que parezca, pienso que un alto porcentaje de las peores opiniones de mi corte - no en lo resolutivo sino en lo argumentativo- han sido unánimes (Scalia citado por Saldaña Cuba 2012, p. 151).

Demás está decir que este test más ácido complica también las cosas para las mayorías que, sin mala fe o con ella, quieran basar sus decisiones en criterios extrajurídicos. Como lo explica Lynch para el caso de los disensos judiciales, para la mayoría el tener que contrastar lo que exponga con los argumentos de la minoría hace que disminuya la facilidad con la que el proceso puede escaparse del campo del derecho (Lynch citado por Saldaña Cuba, 2012, p. 148).

Naturalmente, para que todo esto pueda funcionar según lo descrito es importante que la escritura del voto se dé antes de la emisión del laudo, de manera que pueda producir cambios en él y, asimismo, que el voto disidente sea comunicado a las partes ${ }^{24}$. Si la mayoría sabe que el voto disidente no llegará a las partes, este no tiene cómo incentivarlas: se vuelve un discurso que se da en una caja cerrada.

Es evidente también que, cuánto más éxito tenga la tendencia a hacer públicos los laudos (y disensos), más "mercado" es el que podrá mirarlos y más fuerza tendrá el voto disidente para cumplir con los antes descritos objetivos.

\section{Y no se pierde lo que se dice}

Ahora bien, una vez visto que el voto disidente sí tiene algo -y algo grande- que aportar al proceso arbitral en el que se produce, el problema pasa por ver si no es mayor lo que pone en riesgo que lo que aporta. Y lo que se pone en riesgo, según lo que hemos visto, sería la autoridad del laudo y la confidencialidad de la deliberación.

El argumento de la autoridad del laudo, pese a lo claro que parece, oculta una gran falacia, por lo menos si lo vemos a nivel sistémico. Si todos los laudos fueran unánimes, esa unanimidad valdría poco en cada uno de ellos porque se sabría impostada. Si la unanimidad puede tener peso, si puede conllevar un mensaje, este viene precisamente de que se sepa que los disensos son posibles y que, pudiendo cualquiera de los árbitros optar por di- sentir sin ser considerado por ello una especie de traidor al oficio, las razones del laudo convencieron a todos. De ese modo, buscar que la unanimidad reine en el arbitraje para fortalecer su prestigio es querer que este prestigio sea como el del emperador desnudo en el cuento: un engaño que no engaña a nadie.

Por otro lado, ya al nivel de cada proceso concreto, la autoridad central del laudo tendría que venir del acuerdo entre las partes. Del acuerdo, esto es, de someterse a lo que la mayoría del tribunal decidiese según su mejor entendimiento del derecho aplicable. La unanimidad puede sumarle a esta autoridad, evidentemente (siempre y cuando todos los lados no sean unánimes en el sistema), pero esta mayoría debería de bastar. A fin de cuentas, la verdad del derecho para cada caso específico siempre pasa por una cuestión de interpretación y normalmente ofrece espacio para el debate entre posiciones razonables.

Una vez aceptada esta realidad (lo que no es fácil si se pretende que el derecho es ciencia en un sentido diferente al metafórico), no hay razón por la cual un buen disenso podría restar autoridad al laudo. Más bien al contrario: al menos donde hay buena fe por parte de la mayoría y la minoría, unos buenos argumentos de disenso son solo una magnífica prueba para que la mayoría -si luego de verlos opta por reafirmarse- mejore los suyos. Algo así como el fuego que prueba los metales preciosos.

Claro, si llega a suceder que la mayoría no pudo mejorar sus argumentos y los del disenso la dejan de alguna manera en evidencia (el metal no pasa la prueba del calor), entonces lo que tenemos es que las partes no eligieron bien a su tribunal. Un dato que en nada debiera restarle valor a la decisión de este: lo central, repetimos, es que ellas acordaron libremente someterse a las razones que fuese capaz de producir el tribunal que eligieron. Una vez este tribunal funcionó según lo acordado, ya solo toca recordar que, como dice Born, "las malas razones siguen siendo razones" (2014, p. 3044). Lo contrario es estar dispuesto a superponer al razonamiento de los árbitros que las partes han elegido aquello que a los jueces de anulación parezcan "buenas razones". Justamente lo que se quiso evitar al ir hacia un arbitraje: someter el fondo del asunto a la jurisdicción ordinaria.

24 Ambas cosas fueron objeto de debate al interior de un Grupo de Trabajo que armó la CCl para el tema. Su Informe Final del año 1991 consideró que, de hecho, el disenso debería de ser enviado a los árbitros de la mayoría "antes del escrutinio de su laudo por la Corte [de la CCl]" $(\mathrm{CCl}$, párr. 19, 1991) pues "esto le daría a la mayoría la posibilidad de reconsiderar su laudo antes de enviarlo a la Corte [para su escrutinio por esta]" (párr. 19, 1991).

El informe también concluyó que las opiniones disidentes debían ser enviadas a las partes junto con los laudos, salvo en los casos en que su escrutinio por la Corte determinase que ponían en riesgo la validez o ejecución del laudo (aspectos sobre los que la Corte de la $\mathrm{CCl}$ hace su propia revisión). Ambas políticas son las que aplica la $\mathrm{CCl}$ hasta hoy con sus disensos. 
Cuando sucede que una de las partes intenta usar el disenso para alegar una causal de nulidad por defecto de motivación, lo que afecta la autoridad del laudo no es el disenso en sí, sino la deslealtad de la parte que, al perder, decide ignorar el pacto que firmó.

Por otro lado, cuando lo que tenemos es malos argumentos en el disenso, tampoco hay un problema con la autoridad del laudo, sino más bien una reafirmación por contraste del peso de sus razones. Acá lo que tenemos es un fuego que no quema.

Tema aparte es el segundo tipo de disenso: el que señala faltas al debido proceso y, por lo tanto, pone directa o indirectamente en duda al arbitraje en su conjunto. Aquí sí podemos hablar de un ataque directo a la autoridad del laudo y, en consecuencia, del equivalente arbitral de presionar un botón nuclear. Sin embargo, no en todos los casos aquello implicará una traición al proceso, pues se presentan dos posibilidades: que la acusación tenga razón o que no la tenga.

Si es que la tiene, la autoridad atacada es una autoridad falseada y la acusación sirve definitivamente al proceso (al que fue pactado, no al que se llevó a cabo). El árbitro que, en ese caso, disiente para hacer esta acusación, no está traicionando al arbitraje: el arbitraje ya fue traicionado y él solo está denunciando dicha traición.

Se puede pensar que hay otros caminos mejores para esa denuncia, particularmente el de una acusación ante el centro que administra el arbitraje, cuando se trata de un arbitraje institucional, o ante la autoridad encargada de velar por el ejercicio ético de la profesión (como el Colegio de Abogados) en el caso de un arbitraje ad hoc. No obstante, ninguno de esos caminos sirve tan directamente para lo que-siempre en el supuesto de que la denuncia tenga buena base- se debería hacer: la anulación del laudo.

$\mathrm{Si}$, en cambio, este disenso-acusación se hace sin una base sólida, estamos ante un supuesto de mala fe o negligencia grave del árbitro, vuelto -ahora sí- en el quintacolumnista del arbitraje. Sin embargo, esto no se puede determinar a priori como para que tenga sentido limitar o cortar en general la posibilidad de otorgar este tipo de disensos. Para los abusos existen controles más lógicos, considerando la naturaleza del arbitraje, como veremos en un momento.

El otro problema es la confidencialidad. Se dice que el disenso puede violentarla, al revelar aspectos de las deliberaciones. Pero este es, nuevamente, un tema que no se puede asumir a priori. Habrá disensos que violen la confidencialidad y disensos que no. Más aún, igual que en el caso anterior, existirán disensos que serán saludables -que servirán al arbitraje- al violarla: aquellos que necesiten hablar sobre el contenido de las deliberaciones para probar una violación al debido proceso. La confidencialidad está ahí para proteger a los procesos válidos, no a los atentados contra estos. No es por gusto que, como hemos visto, hasta Van den Berg acepte el voto de disenso en esta situación.

A este respecto, es muy ilustrativo el antes citado caso de Vantage Deepwater c. Petrobras America (2018). En él, James Gaitis se quedó atrapado como árbitro en las cadenas que había planteado para el disenso como académico. Porque si el juez decidió que no había mérito suficiente para entrar a ver si efectivamente había ocurrido lo que Gaitis denunciaba en su opinión disidente (que incluía, como hemos descrito, una acusación de corrupción por parte de la mayoría) fue porque consideró que este no había mostrado ninguna evidencia en el único párrafo que componía su voto. El juez se preguntó por qué Gaitis, un experto autor de varios libros en el campo del arbitraje, no incluyó más detalles en su disenso si tenía una opinión "tan fuerte". Por su parte, Gaitis hizo un disenso de un solo párrafo porque, como dijo en el propio texto del voto, eso era lo coherente con lo que él había escrito antes sobre de los disensos arbitrales: que, cuando se dieran, debían ser "desapasionados y discretos" (en la línea de Redfern) (2018, nota 1). Demasiado corto y discreto para convencerlo de seguir mirando el asunto, le pareció al juez.

\section{Entonces, ¿cómo debería verse al disenso?}

En tanto que el disenso, como hemos visto, tiene aportes claves que hacer al tribunal-incluyendo el de asegurar que este funcione con todas sus partes- $y$ en tanto que estos aportes dependen de los argumentos que se expongan, el disenso debería de ser, antes que nada, libre. Tan libre como el laudo de la mayoría que, dicen los buenos tratadistas, debería de tener como límite lo necesario para hacer su punto: las razones que la llevaron a decidir lo que decidió ${ }^{25} 26$.

25 En su clásico ensayo sobre la motivación en los procesos judiciales (que en realidad contiene razones aplicables a todo proceso adjudicativo), Bingham escribe sobre el contenido de una decisión: "Ninguna carta que el juez haya considera significativa [para su decisión] debe permanecer volteada. Su decisión puede ser luego juzgada como correcta o incorrecta, pero [luego de leer su sentencia] no debe de quedar duda por qué decidió lo que decidió" (1988, pp. 141-145).

26 Evidentemente, esto no quita que cuando escribe su disenso (igual que cuando escribe un laudo) un árbitro siga sometido a sus obligaciones de diligencia, imparcialidad (lo que le obliga a no hacer disensos motivados por el deseo de 
Poner al disenso cortapisas de extensión y alcance (restringido) a lo Redfern, es mandarlo a cumplir su misión esposado, tal y como descubrió Gaitis a la hora de emitir su voto. Y cuidado que, si Gaitis estuvo esposado para hacer su acusación de violación del debido proceso sin poder exponer mínimamente el mérito de esta, hubiera estado absolutamente imposibilitado de moverse si lo que hubiese querido hacer en su disenso hubiera sido una argumentación sobre el fondo que discrepase de la de la mayoría.

Por su parte, las cortapisas de ocasión como las que propone Van den Berg tampoco funcionan. Quedan fuera de sus reglas todos los disensos que no contienen acusaciones de faltas al debido proceso pero que, por todo lo expuesto líneas arriba, tienen sí mucho que aportar (desde el eventual cambio de sentido hasta la mejora de calidad del laudo).

La verdad es la que escribe Domenico di Pietro: "el disenso es el mejor juez de sí mismo" (2011). A cada disenso solo se le puede medir por lo que dice y por las circunstancias -laudo de la mayoría incluido- en las que lo dice. Esta es la única y verdadera forma de saber en qué casos un disenso no tiene mejor sustento que el del exhibicionismo o el partidismo y, por tanto, no ayuda al proceso y cuándo sí lo tiene (incluidos los casos en que no por tener sustento de fondo deja de tener también exhibicionismo o partidismo: como hemos dicho, lo relevante son los argumentos y cómo funcionan frente a los de la mayoría).

¿Quién debe medir esto? Pues quien se juega más al medirlo mal: los usuarios. Los usuarios conocen mejor que nadie lo que le sirve a cada uno y lo que no, y, al menos, cuándo existe suficiente información para separar el trigo de la paja son el más efectivo regulador. Por ejemplo, un árbitro que aprieta sin causa justa el botón nuclear del disenso y ataca al proceso será un árbitro que no tendrá buena fama en un mercado (formado por árbitros y abogados arbitrales) que vive de la validez de los laudos. Frente al árbitro que aprieta el botón nuclear en vano, sí tienen sentido los estigmas.

Ciertamente, lo coherente con la naturaleza del arbitraje es dejar que sea el mercado el que decida qué le dice cada disenso sobre quien lo emite. No hay que olvidar que, si el arbitraje está construido sobre una idea de base, esa es esta: nadie mejor que las partes para saber cómo matar las pulgas de su conflicto.

En coherencia con esto, las instituciones que el propio mercado ha creado para el arbitraje transitan crecientemente hacia la transparencia. Por ejemplo, cada vez son más los centros que, inclusive en arbitrajes comerciales, permiten saber quién fue nombrado por quién y cómo laudó. Cada vez es más cierto para el campo arbitral aquello que escribió el juez Brandeis: "la luz es el mejor desinfectante".

Lo que en ningún caso se debe hacer es intentar prohibir o encadenar, sea desde la regulación o desde el estigma social en la comunidad arbitral, una libertad que es connatural a la idea de un tribunal, que tiene mucho que aportar a su buen funcionamiento y que, como toda libertad de expresión, solo puede cumplir sus fines si quien la tiene podrá decir todo lo que quiere decir.

\section{REFERENCIAS}

American Arbitration Association (2004). The Code of Ethics for Arbitrators in Commercial Disputes. https://www.adr.org/sites/default/files/ document_repository/Commercial_Code_of_ Ethics_for_Arbitrators_2010_10_14.pdf

Arroyo, M. (2008). Dealing with Dissenting Opinions in the Award: Some Options for the Tribunal. ASA Bulletin, (26), 437-466.

Bingham, T. H. (1988) Reasons and Reasons for Reasons. Arbitration International, 4(2), 141-145.

Born, G. (2014). International Commercial Arbitration (2da Ed.). Wolters Kluwer.

Cassady, M. (2018, 19 de diciembre). Petrobras Can't Depose Arbitrator In \$622M Award Row. Law 360. https://www.law360.com/articles/1113051/petrobras-can-t-depose-arbitrator-in-622m-award-row

Cámara de Comercio Internacional (CCI). (1991). Final Report on Dissenting and Separate Opinions. ICC International Court of Arbitration Bulletin, 2(1), 32. https://library.iccwbo.org/ content/dr/COMMISSION_REPORTS/CR_0003. htm?|1=bul\#TOC_BKL1_3

contentar a la parte que lo nombró), confidencialidad (lo que le obliga a no revelar lo que dijo cada cual en las deliberaciones), colegialidad (lo que le obliga a mantener un tono educado siempre) (Born, 2014, p. 3057). Solo cabría agregar que la diligencia lo obliga a sopesar bien la necesidad del disenso y la fortaleza de sus argumentos. 
Di Pietro, D. (2011, 24 de octubre). The Controversial Role of Dissenting Opinions in International Arbitral Awards [Entrada de blog]. https:// blogs.law.nyu.edu/transnational/2011/10/ the-controversial-role-of-dissenting-opinionsin-international-arbitral-awards/

Lew, J. D., Mistelis, L.A., \& Kröll, S. (2003). Comparative international commercial arbitration. Kluwer Law International BV.

Redfern, A. (2004). Dissenting Opinions in International Commercial Arbitration: The Good, the Bad and the Ugly. Arbitration International, (20), 223-242.

Saldaña Cuba, J. H. (2012). Los votos Singulares en el Tribunal Constitucional del Perú (tesis para optar el título de licenciado en Derecho). Pontificia Universidad Católica del Perú, Lima, Perú.

Sönderlung, C. (2019, 12 de marzo). Dissenting opinions and why they should be tolerated [Entrada de blog]. https://journal.arbitration.ru/ analytics/dissenting-opinions-and-why-theyshould-be-tolerated/

Strezhnev, A. (2015). You Only Dissent Once: ReAppointment and Legal Practices in Investment Arbitration. Scholars at Harvard. https://scholar.harvard.edu/files/astrezhnev/files/dissent_ draft_1.pdf

Uluc, I., \& Sutton, K. R. (2018). "Without Silence, There is no Golden Rule; Without Dissent, There is no Progress". Oregon Review of International Law, (20), 219-274.

Van den Berg, A. J. (2010). Dissenting Opinions by Party-Appointed Arbitrators in Investment Arbitration. En M. Arsanjani, J. Cogan, R. Sloane \& S. Wiessner (Eds.) Looking to the Future: Essays on International Law in Honor of W. Michael Reisman (pp. 821-843). Koninklijke Brill

\section{LEGISLACIÓN, JURISPRUDENCIA Y OTROS DOCU-} MENTOS LEGALES

CME Czech Republic BV c. República Checa (Neth. c. Czech.), procedimiento CNUDMI, laudo parcial, Hándl, J., disintiendo (13 Sep., 2001). https://www.italaw.com/sites/default/files/ case-documents/ita0179.pdf

Blue Oil Trading Ltd c. Pure Biofuels del Perú, Res. 76 (CCL 2014)

Corte Superior de Justicia de Lima [Perú]. Segunda Sala Comercial. Sentencia recaída en el Expediente 0244-2014, de 17 de abril de 2015.

Decreto Legislativo 1071. Decreto Legislativo que norma el arbitraje. Diario Oficial El Peruano, 1 de setiembre de 2008 (Perú).

Federal Arbitration Act [Estados Unidos]. Pub. L. No. 68-401, 43 Stat. 883 (1925).

Klöckner Industrie-Anlagen $\mathrm{GmbH}$ c. Camerún, Caso CIADI No. ARB/81/2, Laudo, Castañeda, J, disintiendo (21 Oct. 1983) 2 ICSID Rep. 7 (1983).

Svea Court of Appeal [Suecia]. Court of Appeal. Sentencia recaída en el expediente T 873501 , de 13 de setiembre de 2001. Recuperado de https://www.arbitration.sccinstitute.com/ views/pages/getfile.ashx?portalld=89\&docld= 1242805\&propld=1578.

Vantage Deepwater c. Petrobras América, Caso ICDR No. 01-15-0004-8503 (29 de julio de 2018) (Gaitis en disenso).

Vantage Deepwater c. Petrobras América _ (5th Cir 2020), http://newyorkconvention1958.org/ index.php?|v|=notice_display\&id=6337\&opac_ view $=2$ 